Article

\title{
Biofuels and Their Potential in South Korea
}

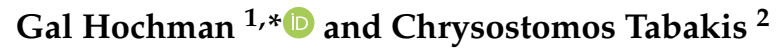 \\ 1 Department of Agricultural, Food, \& Resource Economics, Cook Campus, Rutgers University, \\ New Brunswick, NJ 08816, USA \\ 2 KDI School of Public Policy and Management, Sejong-si 30149, Korea; ctabakis@kdischool.ac.kr \\ * Correspondence: gal.hochman@rutgers.edu; Tel.: +1-848-932-9142
}

Received: 23 July 2020; Accepted: 27 August 2020; Published: 3 September 2020

\begin{abstract}
We investigated the biofuel potential of South Korea and the implications of the introduction of biofuels for the Korean fuel market. We approximated the upper-bound biomass potential from forestry residues, livestock manure, and staple crops and calculated the amount of fuel that could be produced using these different biomass feedstocks. Our assessment suggests that biomass can be used to produce a significant portion of the fuel consumed annually in South Korea, with the most promising feedstock being forestry residues. Out of all the technologies considered, the production of cellulosic ethanol from forestry residues could potentially impact the fuel market the most. The key novelty of our study lies in that we considered a broad portfolio of biofuel technologies and carefully examined their potential economic and environmental implications for South Korea given its biomass availability (which we estimated).
\end{abstract}

Keywords: biofuels; South Korea; biomass; fuel market

\section{Introduction}

South Korea was the ninth-largest energy consumer in the world in 2019 [1]. At the same time, it ranks globally among the top five importers of liquefied natural gas (LNG), coal, crude oil, and refined products, with $98 \%$ of its fossil fuel consumption being covered by foreign supply. However, it does not have any international pipeline infrastructure, and therefore crude oil and LNG are exclusively delivered to South Korea via tankers [2].

The motivation for the introduction of biofuels in South Korea is, in part, based on the costly means currently employed to deliver transportation fuels to its consumers. Energy security-i.e., the uninterrupted availability of natural resources for fuel consumption at an affordable price-is thus an important component of the motivation to incentivize the use of biofuels. Moreover, the penetration of renewable energy technologies in South Korea's fuel market, albeit limited so far, has also been driven by its strategic goal to downscale greenhouse gas (GHG) emissions by $37 \%$ by 2030 as compared with the business-as-usual scenario [3] (see [4] for an analysis of the implications of climate change (and urbanization) for precipitation and temperature in South Korea). In fact, according to the International Energy Agency [5], the transportation sector (including aviation and marine transportation) contributes almost one-fourth of the worldwide $\mathrm{CO}_{2}$ emissions. (According to the U.S. Energy Information Administration [6], on-road transportation in South Korea accounts for the largest share of its transportation energy consumption (as in all regions in the world); at the same time, marine transportation accounts for one-fourth of its total transportation energy use. This latter figure highlights the importance of marine transportation for South Korea, with its economy relying heavily on exports and with major trading partners reached mostly by sea.) Furthermore, the U.S. Energy Information Administration [6] projects an average annual growth of $0.8 \%$ in delivered transportation energy consumption in South Korea over the period 2012-2040. The strategic goal in question has led 
to, among other policies, government-funded research and development (R\&D) activities regarding non-food feedstocks that could be used in the production of fuel for transportation. Still, at this point, there is an urgent need for South Korea to efficiently manage its available natural resources in order to effectively support the growth of its bioeconomy [3].

Biofuels have been traditionally produced from food commodities such as corn (in the United States) and sugarcane (in Brazil), and this has led to a heated food-versus-fuel debate [7,8]. Even though the effect of first-generation (i.e., conventional) biofuels on food commodity prices might be large in the short run, a different picture seems to emerge in the long run. For instance, Hochman and Zilberman [9] demonstrate that the impact of the introduction of corn-ethanol on corn prices in the medium-to-long run is moderate at most. Nonetheless, the perceived impact of first-generation biofuels on food (commodity) prices and their potentially substantial short-run price effects have resulted in a strong push for the use of non-food feedstocks in biofuel production.

With respect to the environment, the benefits of first-generation biofuels are minimal, if any [9]. Nevertheless, it should be noted here that, in comparison with the study by Searchinger et al. [10], the indirect land-use change effect of biofuels has been estimated to be severalfold smaller in more recent studies [9,11-13]. By contrast, advanced (i.e., second- and third-generation) biofuels have great(er) potential for mitigating GHG emissions [14,15].

South Korea is not a big user of biofuels and waste in terms of their share in Total Primary Energy Supply, but it is a relatively large producer of biodiesel as compared with other major Asian economies [16]. In addition, Lim et al. [17] have shown that the gasoline consumers in South Korea are willing to pay a significant premium for the consumption of E5 gasohol (i.e., $5 \%$ bioethanol and 95\% gasoline). On the other hand, Lee et al. [18] argue that South Korea's limited biomass resources along with the high production costs of biofuels present significant barriers to the widespread adoption of biofuels and the achievement of the 2030 implementation targets. However, learning by doing can significantly reduce the biofuel production costs as demonstrated by Goldemberg et al. [19] and Chen and Khanna [20]. In a recent paper, Lee and Huh [21] make projections for South Korea employing the forecasting model for new and renewable energy supply used in the 2014 Fourth Basic Plan for New and Renewable Energy of the Korean government-with the government target for 2035 for the deployment rate of new and renewable energy standing at $11 \%$. Their projections show that Korean new and renewable energy production will reach approximately 37 million tonnes of oil equivalent by 2035, with part of this production coming from biofuels (bioethanol and biodiesel).

Focusing on advanced biofuels, with the development and commercialization of the relevant technologies, the numerous rice-growing areas in South Korea can use the rice straw to produce liquid fuels. Rice straw is an abundant and therefore attractive lignocellulosic material for biofuel production. It has high cellulose and hemicellulose content that can be readily hydrolyzed into fermentable sugars, but challenges do exist [22]. Another promising advanced biofuel feedstock is microalgae, although high production costs-partly due to the challenge of harvesting these photoautotrophic microorganisms-are proving to be a major barrier to microalgae-based biofuel production [23]. Microalgae have been researched in the context of biofuels in South Korea. In particular, as South Korea's energy policies over the past two decades have placed increased weight on the development of green energies, the government has funded several R\&D projects related to algal biofuel production. The underlying reason is straightforward. The Korean government has been gradually implementing higher biodiesel blending mandates, aiming to raise the proportion of biodiesel in the blends to $5-7 \%$ in the near future. However, significant amounts of the feedstocks used in the production of biodiesel are currently imported by South Korea-mainly from Argentina, Brazil, Indonesia, and Malaysia. Thus, the Korean government has been seeking the development of non-food biodiesel farms in order to reduce the reliance on foreign sources for biodiesel production [24]. Finally, miscanthus is another advanced biofuel feedstock that has drawn considerable interest. This interest stems from its high productivity, low input requirements (N2 fertilizer and herbicides), and high content of polysaccharides [25]. 
The potential of biofuels (especially of the advanced ones) for mitigating GHG emissions has led several countries to promote their production and consumption. The European Union, for example, has adopted policies to induce the use of advanced biofuels for transportation that are produced from sustainable sources including residues and wastes [26]. Nonetheless, numerous challenges are present. For instance, Börjesson Hagberg et al. [27] have used the MARKAL Sweden modela dynamic, bottom-up, cost-optimization model covering the energy system in Sweden-to show that, even though system integration of biofuel production could have noteworthy effects on the overall energy system of Sweden, in the long run and under stringent $\mathrm{CO}_{2}$ constraints, it will have limited impact on total biofuel use in the transportation sector. Furthermore, in the United States, the Energy Policy Act of 2005 and the Energy Independence and Security Act of 2007 ushered into the energy markets the Renewable Fuel Standard, which resulted in significant economic gains for its agricultural sector and improved substantially its balance of trade but had relatively minor implications for GHG emissions [9] (see also [28] for a comparison of the costs and benefits of the Renewable Fuel Standard against those of the Low Carbon Fuel Standard introduced by California).

In this paper, we investigate the biofuel potential of South Korea and the implications of the introduction of biofuels for the Korean fuel market. A partial-equilibrium numerical model is employed in our analysis. We first use data from the Korean Statistical Information Service [29] (supplemented with data from the Food and Agriculture Organization of the United Nations [30]) to offer a preliminary assessment of the theoretical (i.e., upper-bound) biomass potential from forestry residues, livestock manure, and staple crops and of the amount of fuel that could be generated using these different biomass feedstocks. Next, we use a linear demand and supply system for the fuel market and calibrate it taking the own-price demand and supply elasticities from the literature. In order to address any uncertainty regarding our model's parameters, we resort to Monte Carlo simulations. More specifically, we simulate different biofuel supply-shock scenarios while randomly perturbing the demand and supply elasticities (separately).

A vast body of literature has investigated the economic and environmental ramifications of biofuels, with many of these papers focusing on corn-ethanol (see [9] and references therein). Regarding the analytical methods used, a large number of papers employ numerical methods in their analysis like in this paper. Moreover, some papers resort to a partial-equilibrium analysis like here (e.g., [31,32]), while others use a computable general equilibrium model (e.g., [11,33]). The key novelty of our study lies in that we consider a broad portfolio of biofuel technologies and carefully examine their potential economic and environmental implications for South Korea given its biomass availability (which we estimate).

\section{Materials and Methods}

Next, we describe the methods and data used in our study. Section 2.1 briefly discusses the partial-equilibrium model underlying our analysis. Section 2.2 offers a description of the data and methodology employed in generating an assessment for South Korea of its theoretical biomass potential and of the amount of fuel that it could produce using different domestic biomass feedstocks. Finally, in Section 2.3, we describe the methodology followed to calibrate the fuel demand and supply functions for South Korea.

\subsection{The Conceptual Model}

When modeling the domestic fuel market of South Korea, we employ a partial-equilibrium analysis [32] because it enables us to highlight the economic and environmental impact of biofuels in a straightforward and clear manner.

Formally, let $p_{g}$ denote the price of gasoline in USD per gallon and assume that demand, $D\left(p_{g}\right)$, is a linear, downward-sloping function. For simplicity, assume that the supply of gasoline, denoted by $S\left(p_{g}\right)$, is a linear, upward-sloping function. Figure 1 depicts the initial equilibrium outcome in the gasoline market, which is the point where demand intersects supply (point $A$ in Figure 1) and marginal cost equals price. The initial equilibrium quantity is $q_{g}^{0}$, and the corresponding equilibrium price is $p_{g}^{0}$. 


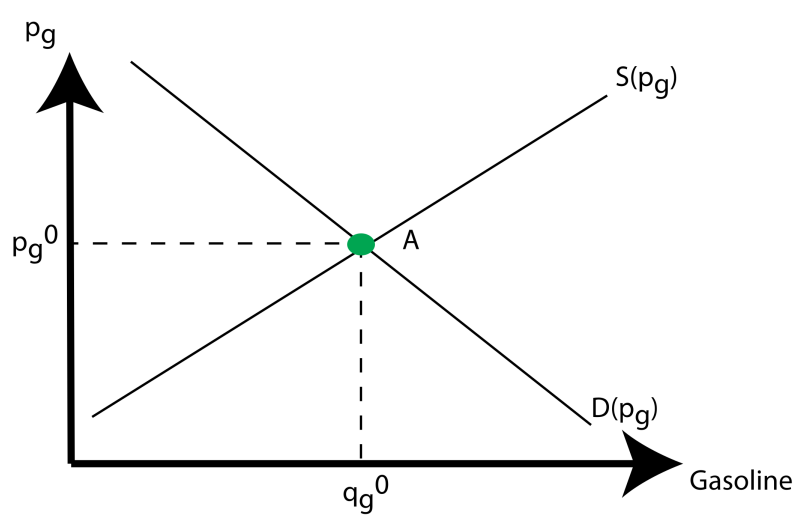

Figure 1. The gasoline market.

How does the introduction of biofuels affect the overall fuel market? To answer this question, we first note that the energy content of ethyl alcohol (i.e., ethanol) per unit of volume is $\beta$ percent that of gasoline (it is about $67 \%$ that of gasoline). We, therefore, assume that the price of ethanol is just:

$$
p_{e}=\beta \cdot p_{g}
$$

For simplicity and brevity, we will henceforth focus on the price per gallon of gasoline-equivalent (GGE), $p_{f}$, where $p_{f}=p_{g}=\frac{p_{e}}{\beta}$.

Next, we posit that the introduction of biofuels results in a shift of the aggregate fuel supply curve down and to the right. (Note that South Korea does not have a blending mandate "forcing" the introduction of bioethanol into its fuel market, which could result in a gasohol price increase [34]. The supply curve shifts downwards here simply due to the introduction of a new fuel source (namely, ethanol). The underlying assumption is that the production cost of ethanol is not prohibitively high as compared with that of gasoline.) More specifically, given the fuel price $p_{f}^{0}$, we assume that the introduction of biofuels in GGE units results in the supply curve shifting down and to the right by $B=\frac{X}{100} \cdot q_{f}^{0}$, where $B$ is the biofuel amount (in units of GGE; see Figure 2).

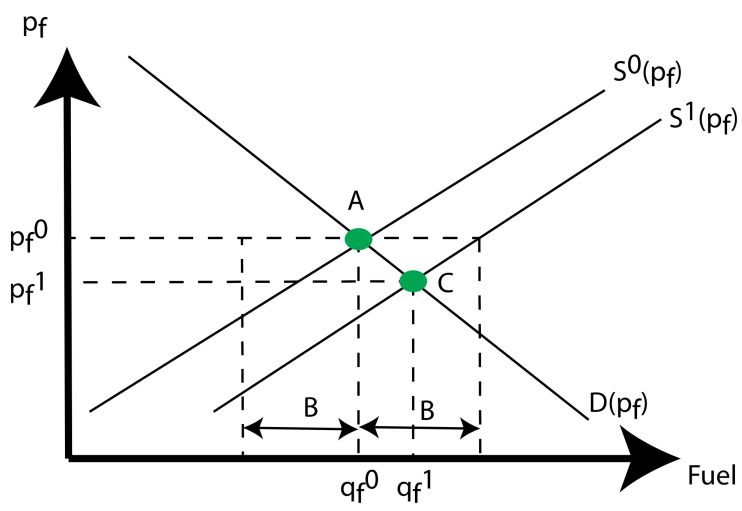

Figure 2. The fuel equilibrium.

\subsection{The Data}

The data used in the analysis comes from two different secondary sources. First, we use the Korean Statistical Information Service to obtain data on forestry residues [29]. Although our focus is on the year 2013, data on forestry is collected in 5-year intervals-that is, data for either 2010 or 2015 could be used in our case. When approximating the theoretical biomass potential, we use the data for 2015. To calculate the potential biomass from forestry residues (in cubic meters), we use the data 
on forest area and volume. We assume an average density of $380 \mathrm{~kg}$ per cubic meter solid volume (similar numbers have been used in the literature (e.g., [35])). The reason is that the data only provides information on the types of trees in South Korea and the aggregate area covered by forest and the volume thereof but not on the area covered per tree type.

Next, we look at livestock manure production. The number of heads of beef cattle, dairy cows and heifers, pigs, and chicken (layers and broilers) is taken again from the Korean Statistical Information Service [29]. The data on chickens only includes information on broilers and layers (that is, it does not include information on breeding chickens). In addition, only chickens in farms that have more than 3000 heads are counted (by complete enumeration). Therefore, the number of chicken heads is underestimated in the data. To get the amount of volatile solids (VS) that each type of livestock produces, the following equation and values are used:

$$
V S=A P \cdot T A M \cdot v S
$$

where:

- AP: Animal Population in number of heads [29];

- TAM: Typical Animal Mass [36];

- $\quad$ vs: average annual VS production per unit of animal mass [36].

The VS amount of each livestock is then converted into GGE using the parameters of NJ [36].

The final group of feedstocks for biofuel production considered in our study consists of staple crops: sorghum, sweet corn, and wheat. The data is taken from the Food and Agriculture Organization of the United Nations [30]. The data is in metric tons (for the year 2013). We convert the values to GGE of biofuels applying the net usable percentage and percent of dry matter parameter values as obtained from NJ [36].

In sum, we use the energy conversion parameters of NJ [36] to assess the biofuel potential of South Korea (Table 1). It should be noted here that some of these parameters are preliminary estimates (used in the literature) as the respective technologies are only at the research and development stage.

Table 1. Biomass assessment. GGE: gallon of gasoline-equivalent.

\begin{tabular}{cccc}
\hline Feedstock & Feedstock Technology & Quantity (GGE) & $\begin{array}{c}\text { Energy Conversion } \\
\text { (GGE Per Dry Ton) \& }\end{array}$ \\
\hline Crop & Ethanol from starch & 6500 & 2.6 \\
Sorghum & Ethanol from starch & 51,465 & 2.7 \\
Wheat & Cellulosic ethanol & $1,699,743$ & 95.2 \\
& Gasification-F-T & 739,174 & 41.4 \\
& Dilute acid hydrolysis & $1,274,807$ & 71.4 \\
Sweet corn & Cellulosic ethanol & $7,175,373$ & 95.2 \\
& Gasification-F-T & $3,120,383$ & 41.4 \\
Livestock & Dilute acid hydrolysis & $5,381,530$ & 71.4 \\
Beef cattle & & & 71.2 \\
Dairy cows and heifers & Anaerobic Digestion/Landfill & $230,098,749$ & 71.2 \\
Pigs & gas to transportation fuel & $14,923,062$ & 71.2 \\
Chicken & & $55,772,707$ & 57.9 \\
Forestry residues & & $38,864,666,122$ & 95.2 \\
& Cellulosic ethanol & $16,901,230,856$ & 41.4 \\
& Gasification-F-T & $29,148,499,592$ & 71.4 \\
\hline
\end{tabular}

\footnotetext{
\& Energy conversion parameters taken from NJ [36].
} 


\subsection{Calibration}

We now calibrate the fuel demand and supply functions for South Korea assuming the following linear system of equations:

$$
\begin{aligned}
& p_{f}=\alpha_{0}-\alpha_{1} \cdot q_{f} \quad \text { (the demand equation) } \\
& p_{f}=\gamma_{0}+\gamma_{1} \cdot q_{f}
\end{aligned}
$$

Then, using the definitions of the own-price demand and supply elasticities, we solve for the slope of the respective equation as follows:

$$
\begin{aligned}
& \alpha_{1}=-\frac{1}{\eta_{d}} \cdot \frac{p_{f}^{0}}{q_{f}^{0}} \\
& \gamma_{1}=\frac{1}{\eta_{s}} \cdot \frac{p_{f}^{0}}{q_{f}^{0}}
\end{aligned}
$$

where $\eta_{d}$ denotes the own-price demand elasticity and $\eta_{s}$ denotes the own-price supply elasticity. We subsequently use the slopes of the demand and supply curves calculated above to calibrate the intercepts of the two equations:

$$
\begin{aligned}
& \alpha_{0}=p_{f}^{0}+\alpha_{1} \cdot q_{f}^{0} \\
& \gamma_{0}=p_{f}^{0}-\gamma_{1} \cdot q_{f}^{0}
\end{aligned}
$$

The elasticity of the Korean fuel demand used in the baseline scenario is taken from Hochman and Timilsina [37] and equals -0.5755 . By contrast, we could not find information on the elasticity of fuel supply for South Korea. Thus, in the baseline scenario, we use the value of 0.3, which is in line with the values used in the literature $[34,38,39]$.

Given the uncertainty regarding these parameters, we then randomly perturb the demand and supply elasticities separately through Monte Carlo simulations. More specifically, we perform 1000 Monte Carlo trials for each of the different biofuel supply shocks we consider (to be discussed below). For the random sampling, we use a triangular distribution for the own-price demand elasticity (with parameters $-1.05,-0.5755$, and -0.16 ) and a truncated normal distribution for the own-price supply elasticity (with a mean of 0.3 and a standard deviation of 0.1 ), with the demand elasticity being always negative and the supply elasticity being always positive.

When calibrating the demand and supply curves, we use data on gasoline consumption and price for the year 2013 as reported by the Korean Statistical Information Service [29]. The quantity is taken directly from the site, and the price, in USD per gallon, equals the ratio of gasoline expenditure divided by the gallons of gasoline consumed.

\section{Analysis and Results}

The biomass assessment suggests that, theoretically, biomass can be used to produce a significant portion of the fuel consumed annually in South Korea. Although the political-economic potential is probably much smaller than the theoretical one [40], it is likely to still be substantial for the fuel market of South Korea-an economy that currently depends on imports of crude oil and that has no domestic oil reserves it can harness.

Table 1 (see Section 2.2) presents the results of our biomass assessment by summarizing the potential for biofuel production from various crops, livestock manure, and forestry residues. In theory, the most promising feedstock is forestry residues, whereas the staple crop potential is minimal, which is consistent with the fact that South Korea imports almost all of the wheat and sweet corn it consumes. Furthermore, out of all the technologies considered, the production of cellulosic ethanol from forestry residues could potentially impact the fuel market the most. The theoretical amount of cellulosic ethanol that could be produced from forestry residues is 38.86 billion GGE, which equals 122.3 million tonnes of oil equivalent. Note here that, in 2017, South Korea consumed 137.97 million tonnes of oil equivalent 
of petroleum and other liquids [2]. In addition, our analysis shows that the introduction of biofuels results in a decline of the fuel price to end consumers and in an increase in the total amount of fuel consumed-which is in line with the fact that $q_{f}^{1}>q_{f}^{0}$ and $p_{f}^{1}<p_{f}^{0}$ in Figure 2. For instance, if beef cattle manure was utilized for fuel production, the fuel price could fall by $8.2 \%$ (using the baseline parameters); if pig manure was used instead, the price of fuel could drop by $5.3 \%$ (as Table 1 illustrates, 230,098,749 GGE of biofuel could be produced in the former case, and 148,772,707 GGE of biofuel could be produced in the latter one). On the other hand, if forestry residues were utilized, the shock to the fuel market could be of such magnitude that the market price of fuel would collapse.

Before proceeding further, a few remarks are in order. When assessing the net benefits from the development and deployment of biofuels, the direct (and indirect) costs associated with their production should be carefully accounted for. However, some of the technologies listed in Table 1 are only at the research and development stage and have not been commercialized yet, and some of the others that have been commercialized are currently employed to a limited extent only and are gradually becoming cost-competitive (e.g., production of landfill gas or production of biogas by anaerobic digestion). Nonetheless, learning by doing and learning by researching can be very substantial in the renewable energy industry, which suggests that renewable technologies should be evaluated from a dynamic point of view. In fact, this is definitely the case for advanced biofuels. For instance, according to the National Renewable Energy Laboratory [41], the modeled cost of cellulosic ethanol production decreased from $\$ 9.00 /$ gallon to $\$ 2.15 /$ gallon (i.e., a $76.1 \%$ drop in production cost) over the period 2002-2012 (see also [42] and Figures 13 and 14 therein). Lastly, it is important to remember that many biofuels yield lower lifecycle GHG emissions than fossil fuels. This implies that, from a Pareto efficiency perspective, whether a biofuel can provide net benefits to the society (or not) depends not only on its cost competitiveness but also on its environmental benefits and costs vis-à-vis its fossil-based counterparts. Put differently, the cost advantage of fossil-based fuels vis-à-vis (most) biofuels in part stems from the fact that the high environmental (and health) costs associated with the former are not reflected in their market price (in the absence of government policy).

Because of the many unknown parameters, which depend as we just discussed, among others, on the research and development of biofuel technologies and their commercialization and adoption, we simulate various biofuel supply-shock scenarios. To this end, we employ the Monte Carlo methodology described in Section 2.3 and analyze different supply-shock scenarios randomly perturbing first the demand elasticity. In Figure 3, we depict the distribution of the changes in the total quantity of fuel consumed arising from 1000 Monte Carlo simulations for two alternative biofuel shocks: $5 \%$ and $25 \%$ of the total gasoline consumed in South Korea in the year 2013. (We present the simulation results for these two shocks as they can be reasonably viewed as a "modest" and an "ambitious" biofuel scenario for South Korea. The simulation results for other supply shocks are available from the authors upon request.) The distribution of the changes in the fuel price for these two shocks is depicted in Figure 4. In the case of the 5\% shock, total fuel consumption increases, on average, by $3.3 \%$ (see Figure 3), while the market price of fuel decreases by $5.8 \%$ (see Figure 4 ). The $25 \%$ shock yields similar results in terms of sign, with the price declining (on average) by $29 \%$ and the total quantity of fuel consumed increasing by $16.3 \%$. The main difference-which stems from the assumption of a linear demand function and the fact that the biofuel amount introduced in the second scenario (namely, the $25 \%$-shock one) is substantially larger-is that the distributions of price and quantity changes in the $25 \%$-shock scenario are more dispersed. 


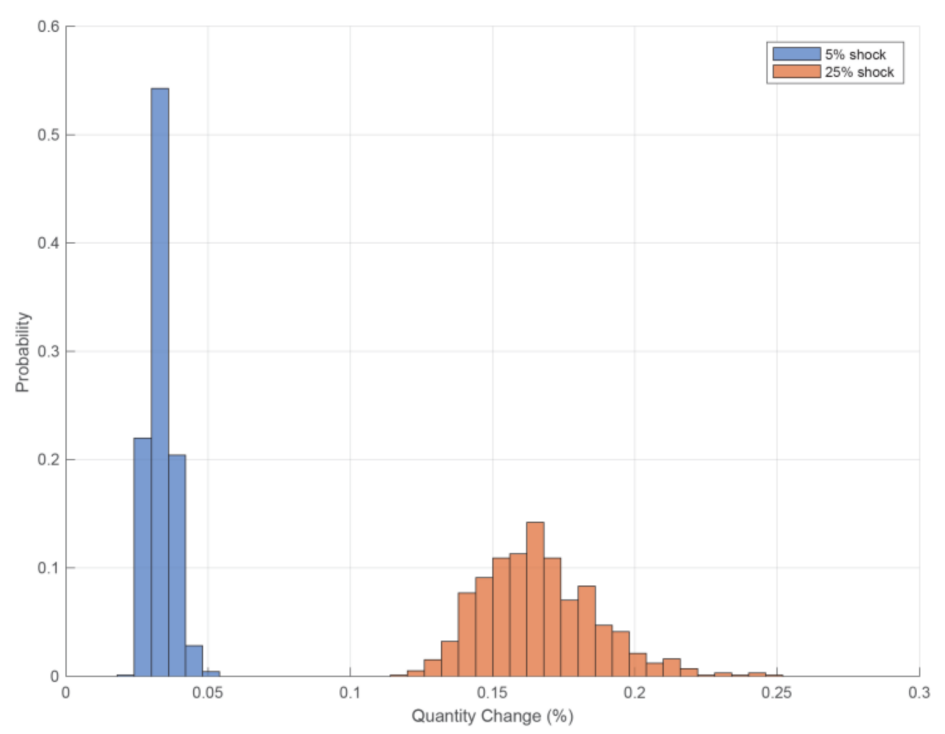

Figure 3. Change in fuel consumption after supply shock (demand simulations).

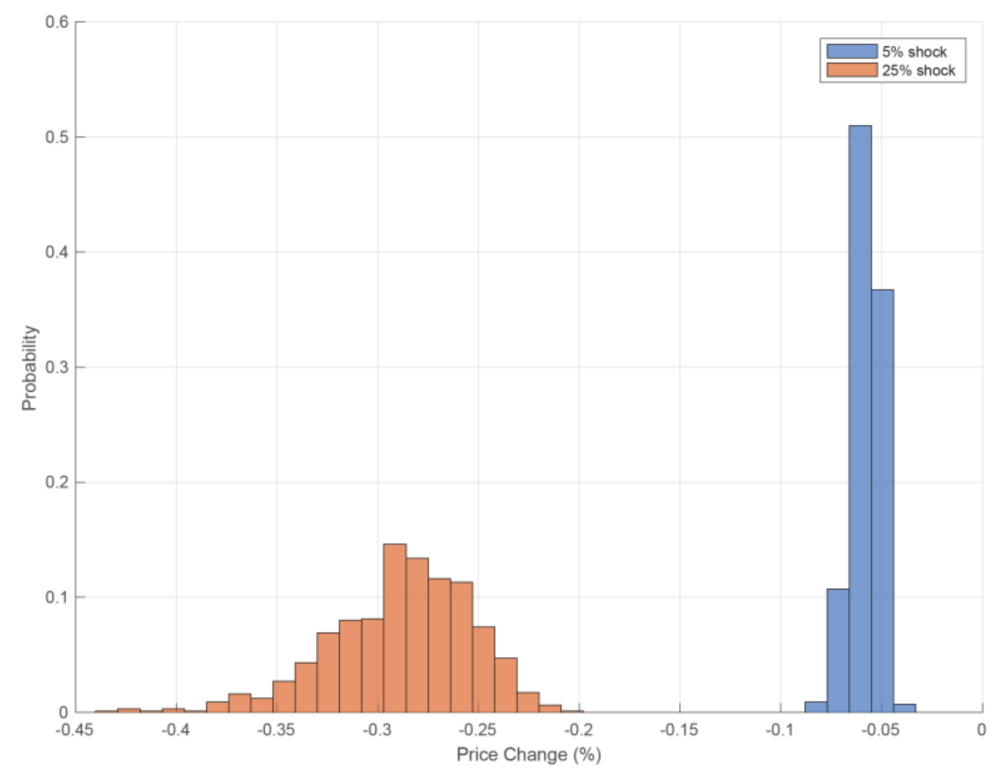

Figure 4. Change in fuel price after supply shock (demand simulations).

Since the introduction of biofuels leads to a drop in the fuel price, it gives rise to an environmentally detrimental-with respect to reduction in $\mathrm{CO}_{2}$ emissions-rebound effect as the demand for gasoline declines by less than the GGE amount of the biofuels introduced (see Figures 5 and 6; in terms of Figure 2, point $C$ (the new equilibrium) is down and to the right of point $A$ (the initial equilibrium), and the new amount of gasoline consumed is $q_{f}^{1}-B>q_{f}^{0}-B$ - the rebound effect, then, equals in this case $\frac{q_{f}^{1}-q_{f}^{0}}{B}$ ). In Figure 7, we depict this rebound effect. In particular, a $5 \%$ biofuel shock results in a decline of only $1.7 \%$ (on average) in the total amount of gasoline consumed. That is, it results in a $65.2 \%$ rebound effect. Similarly, the $25 \%$ biofuel shock leads to a decrease in the total quantity of gasoline consumed by $8.7 \%$. Clearly, the rebound effect does mitigate the environmental benefits from the introduction of biofuels. In the $5 \%$-shock scenario, $\mathrm{CO}_{2}$ emissions are reduced by just 54,612 tonnes; under the $25 \%$-shock one, $\mathrm{CO}_{2}$ emissions are mitigated by 0.27 million tonnes. 


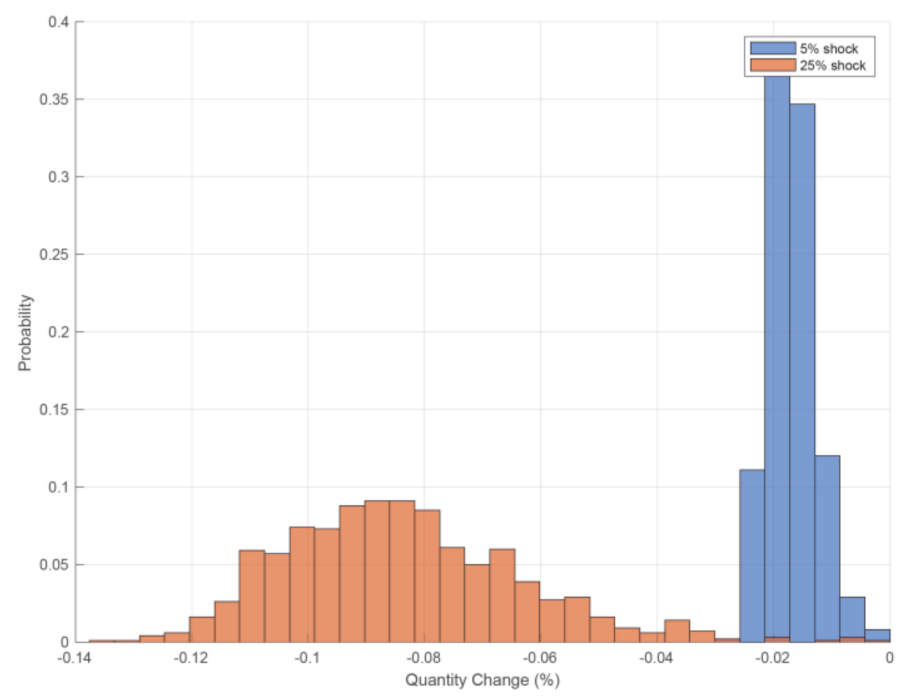

Figure 5. Change in gasoline consumption after supply shock (demand simulations).

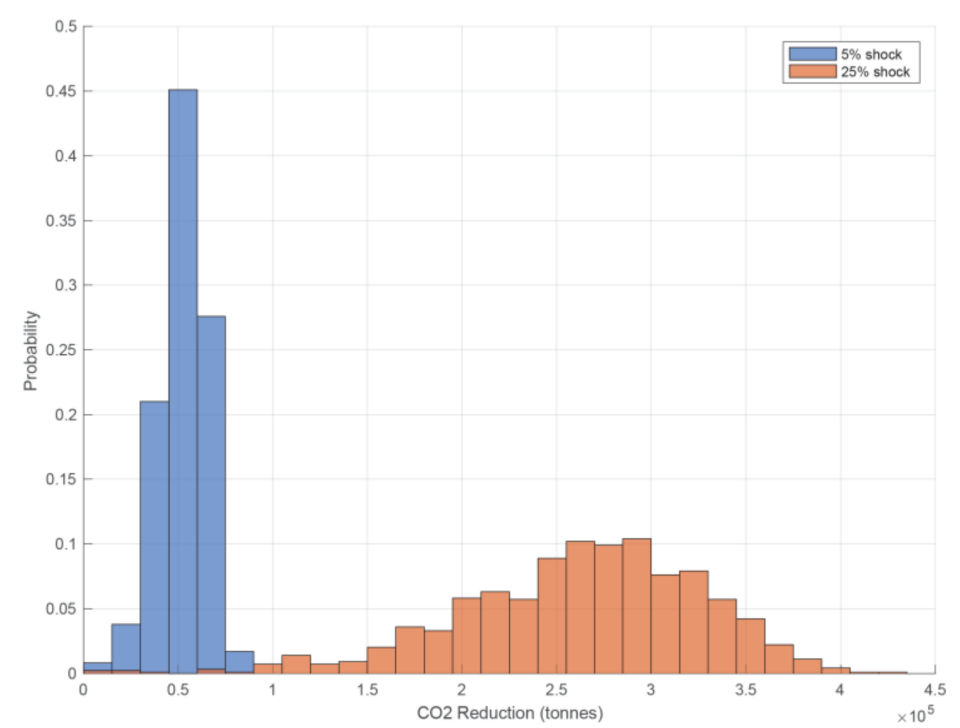

Figure 6. Change in $\mathrm{CO}_{2}$ emissions after supply shock (demand simulations).

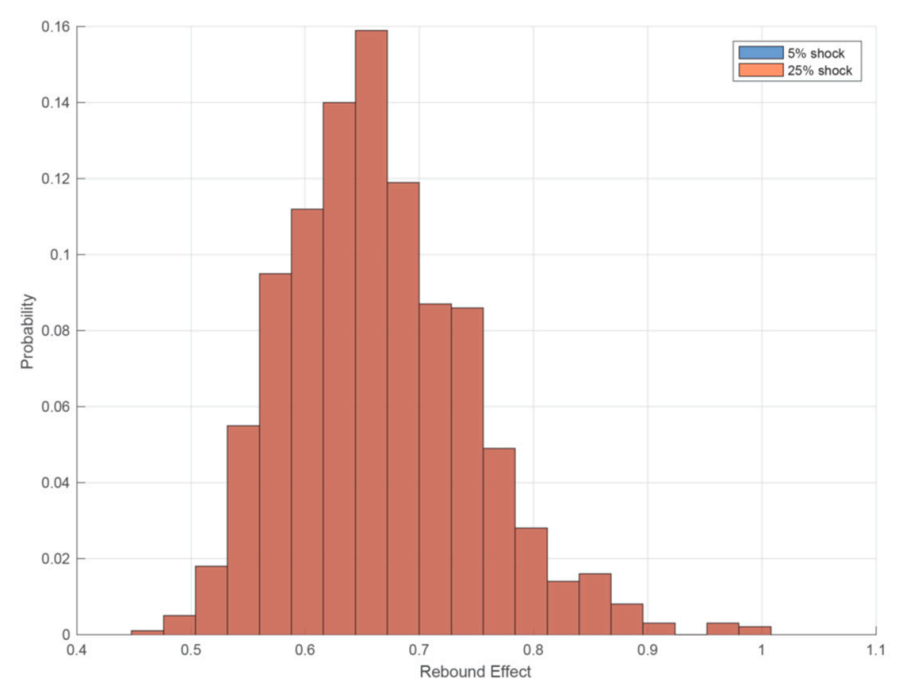

Figure 7. Rebound effect on gasoline consumption after supply shock (demand simulations). 
Our next step is to randomly perturb the supply elasticity, sampling 1000 times-for each supply shock under consideration-from a truncated normal distribution with a mean of 0.3 and a standard deviation of 0.1 . The results of these Monte Carlo simulations are displayed in Figures 8-11 and are very much in line with the predictions emerging from the demand-elasticity simulations. Under the $5 \%$-shock scenario, the market price of fuel decreases, on average, by $5.8 \%$, while total fuel consumption increases by $3.4 \%$. As expected, the $25 \%$ biofuel shock has more pronounced effects on the fuel market, leading to a $29.1 \%$ drop in price and a $16.8 \%$ increase in the quantity of fuel consumed (see Figures 8 and 9). Regarding the environmental benefits from the introduction of biofuels, under the conservative $5 \%$-shock scenario, there is a mere $1.6 \%$ drop in gasoline consumption (implying a $67.1 \%$ rebound effect), reducing $\mathrm{CO}_{2}$ emissions by 51,665 tonnes. On the other hand, under the (more) ambitious $25 \%$-shock scenario, gasoline consumption decreases by only $8.2 \%$, mitigating $\mathrm{CO}_{2}$ emissions by 0.26 million tonnes.

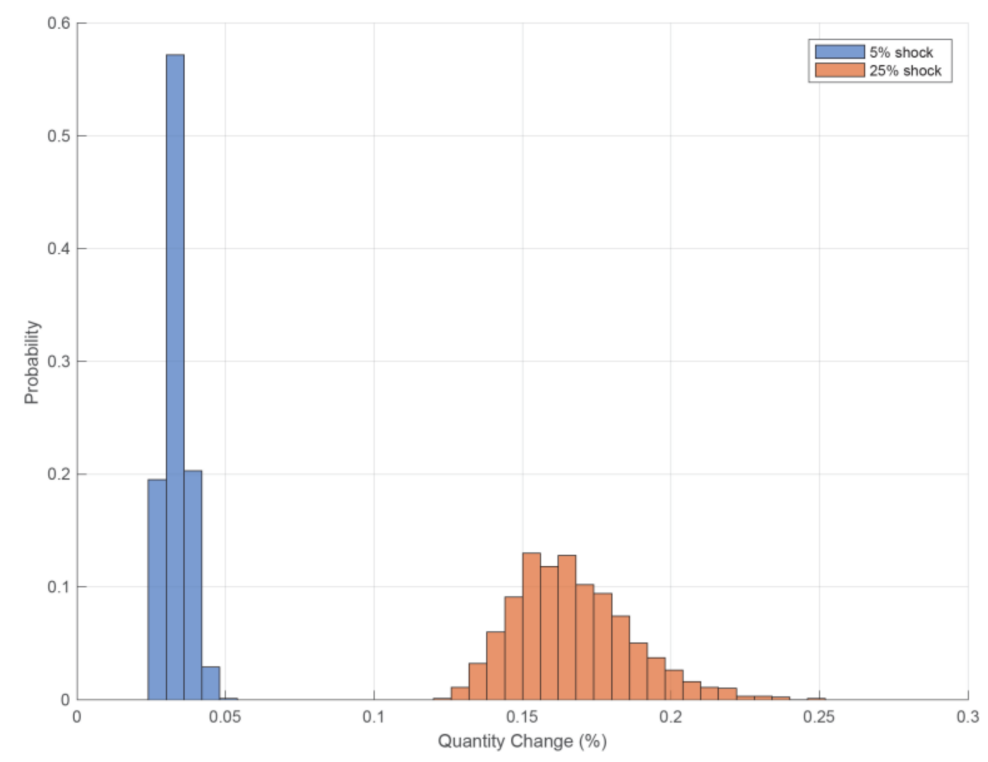

Figure 8. Change in fuel consumption after supply shock (supply simulations).

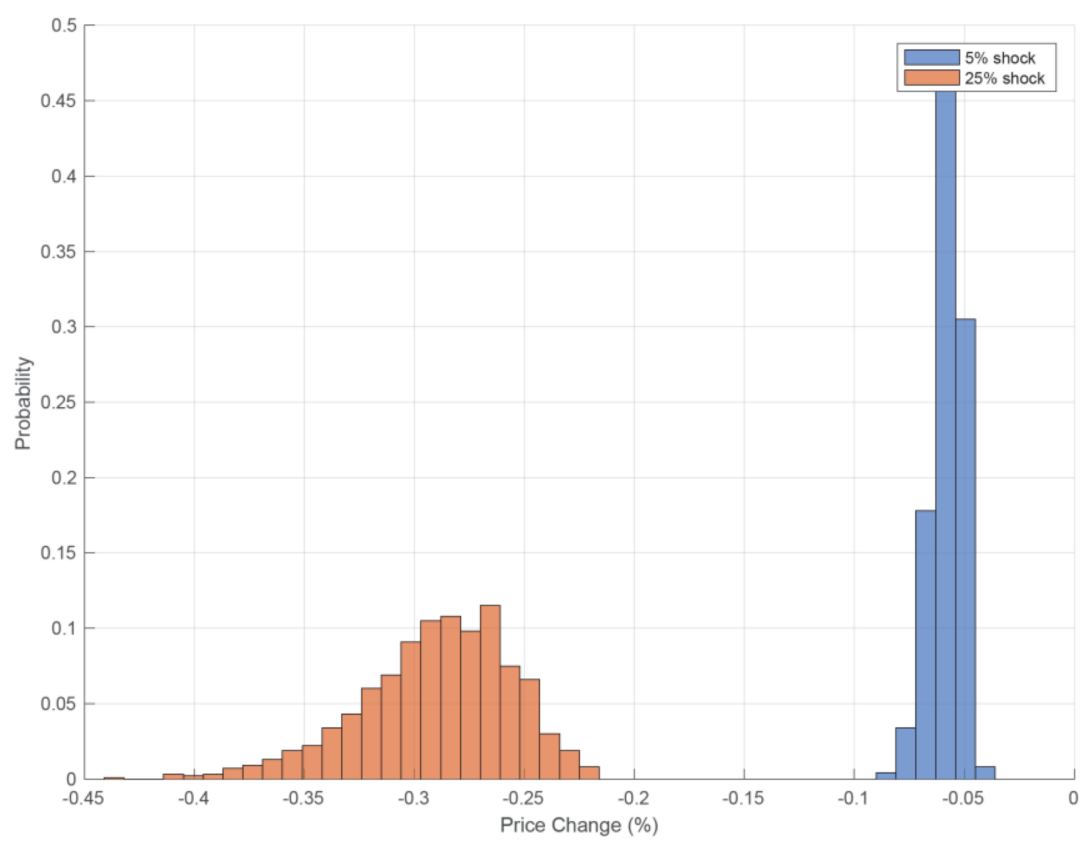

Figure 9. Change in fuel price after supply shock (supply simulations). 


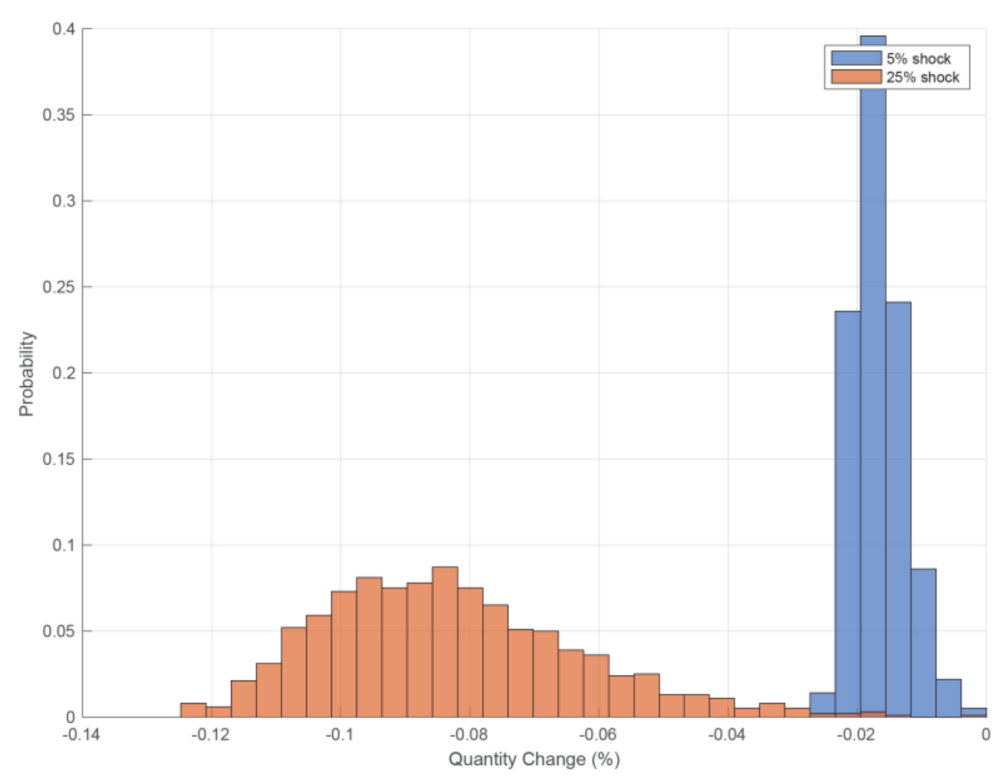

Figure 10. Change in gasoline consumption after supply shock (supply simulations).

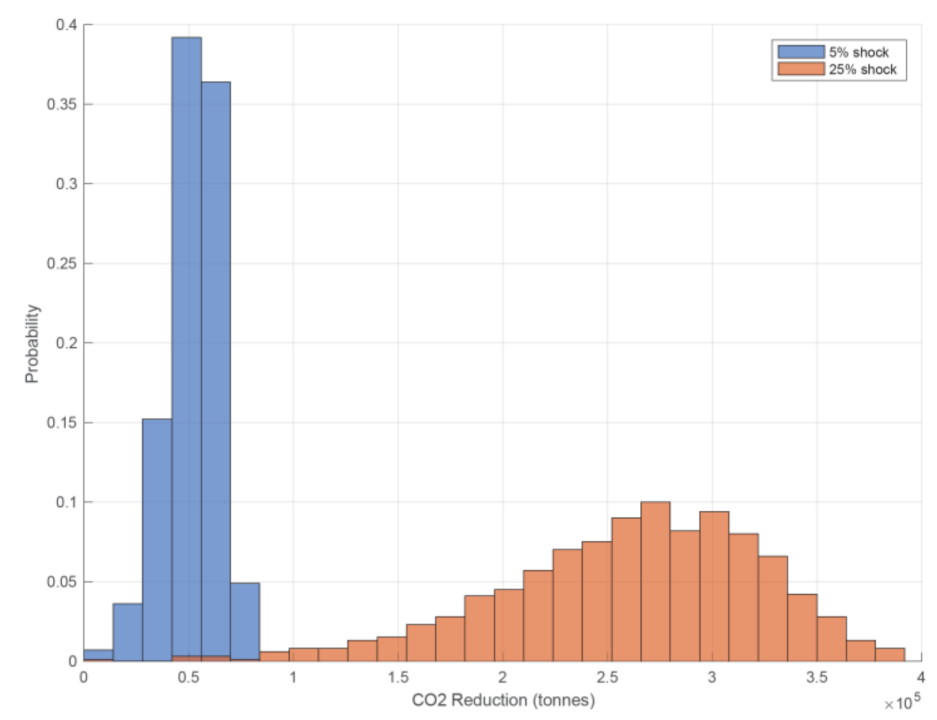

Figure 11. Change in $\mathrm{CO}_{2}$ emissions after supply shock (supply simulations).

Overall, the introduction of biofuels produces a net welfare gain (see Figure 12). More specifically, we look at the ramifications of different biofuel supply shocks for consumer surplus, the surplus of gasoline producers, and the total revenue from biofuel production (using the baseline parameters). The changes in the surpluses/revenue over different biofuel supply shocks are depicted in Figure 12, where the sum of the three changes (i.e., welfare change) is positive and increasing over the range of the shocks considered. Obviously, the total gain for the Korean economy is lower than the welfare gain illustrated in Figure 12 because the biofuel production costs need to be taken into account. Nevertheless, we do not have reliable cost estimates to use for calculating the surplus of biofuel producers as, for instance, some of the technologies included in our analysis are-as we already discussed above-at the research and development stage and have not been commercialized yet. Having said that, the effect on consumer surplus is large and more than likely to compensate for the biofuel production costs. 


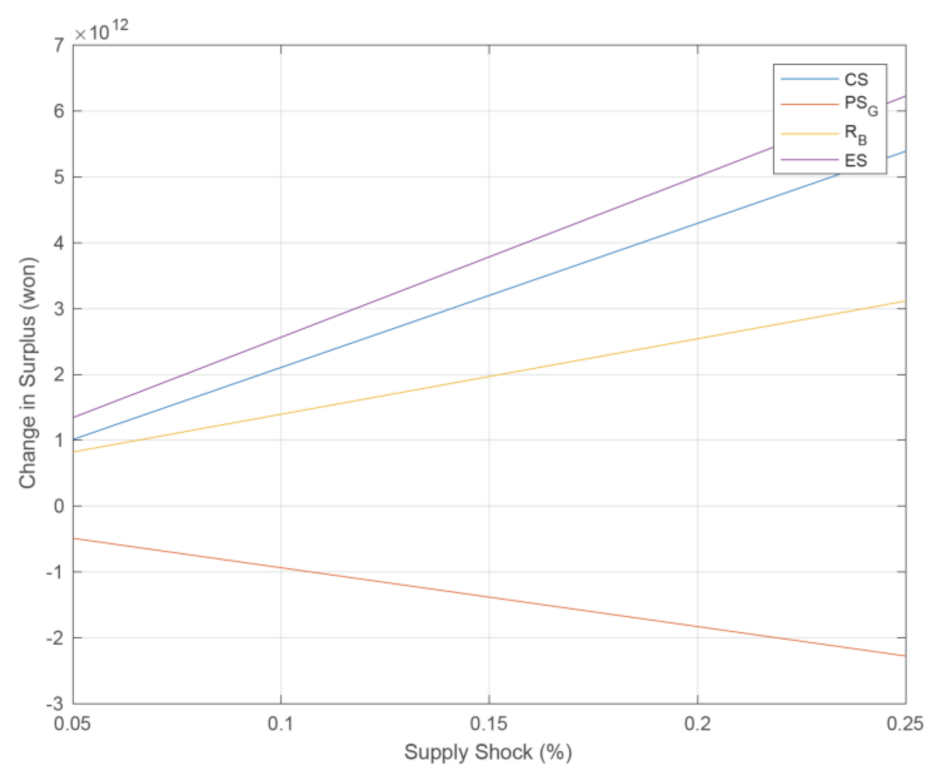

Figure 12. Welfare change (baseline parameters).

\section{Discussion and Policy Implications}

One gap we believe future work should address is a more detailed and thorough assessment of the biofuel potential of South Korea than that presented in Table 1. This assessment should take into account the spatial distribution of the domestic biomass resources-which is not feasible, to the best of our knowledge, with the data currently available - thus identifying regional biofuel production pathways and potential supply chain structures that are or could become economically viable (in the future). Moreover, this assessment should explicitly consider political-economic and logistical constraints, such as policy and institutional barriers, political constraints, and harvesting and transportation constraints (related to the infrastructure in place). Such a thorough assessment will more accurately evaluate the economic viability and the environmental ramifications of biofuel production in South Korea.

We should further note here that, given the experience with first-generation biofuels and the fact that the biofuel potential of staple crops is minimal in South Korea, the realization of the benefits from the introduction of biofuels discussed in Section 3 depends, in practice, both on the success of $R \& D$ activities regarding advanced biofuels and, afterward, on the successful commercialization and adoption of these biofuels. It is true that some of the advanced biofuel technologies considered in our analysis are only at the research and development stage and have not been commercialized yet; furthermore, others that have been commercialized are currently employed to a limited extent only and are gradually becoming cost-competitive. However, if past experience is any guide, learning by doing and learning by researching can be very substantial in the renewable energy industry, suggesting that renewable technologies should be evaluated from a dynamic point of view. In addition, from a Pareto efficiency perspective, whether a biofuel can provide (or not) net benefits to the society depends not only on its cost competitiveness but also on its environmental benefits and costs in comparison with its fossil-based counterparts. In any case, before moving to large-scale development and deployment of biofuels, the impact of their production on food prices should also be investigated and their land-use implications should definitely be explored. We leave these important issues for future research. Overall, as past studies have shown for the United States and Brazil [9,43], biofuels result in net (economic) welfare gains for the country producing and exporting the biofuel commodity while opening up new avenues for its rural communities to prosper. 
A word of caution is, however, in order. Some biofuel companies have been performing very well despite the fact that the price of oil has plummeted (e.g., Poet Biorefining, Elite Octane, Guardian Energy), but others did not thrive and were forced to shut down. Although outside the scope of this work, we should note that a careful examination of the factors that are critical to the economic success and growth of biofuel companies is an important avenue for future research.

Regarding policy, South Korea's light-duty vehicle manufacturers can choose to meet either a fuel economy or a GHG emissions standard. In practice, though, the different metrics are closely related: improvements in fuel economy curb $\mathrm{CO}_{2}$ emissions, and $\mathrm{CO}_{2}$ emissions are a subset of GHG emissions [6]. At the same time, a Renewable Fuel Standard program is in place, mandating oil refiners as well as oil importers and exporters to blend their transportation fuels with a certain amount of biofuels [44] - see [45] for a comparative study of this program versus the Renewable Fuel Standard program of the United States and the Renewable Transport Fuel Obligation program of the United Kingdom. More specifically, for the past three years (more precisely, since July 31, 2018), all diesel fuel has had to contain 3\% biodiesel fuel, and this blending ratio will be reviewed and might be adjusted in 2020 [46]. Given the fact that significant amounts of the feedstocks used in the production of biodiesel are currently imported by South Korea, we believe that the Renewable Fuel Standard program should be supplemented by policy measures aimed at promoting the development and adoption of advanced biodiesel (and advanced biofuels in general) produced from domestically sourced feedstocks. For instance, researching and developing advanced biodiesel for marine vessels may result in very cost-efficient and clean alternatives to the conventional fossil fuels currently used in marine transportation. Of course, passenger vehicles should constitute the main focus of the Korean government's policies as they consume almost half of the total energy consumed by the transportation sector in South Korea [6].

At a broader level, the development of biofuels—a major component of the bioeconomy-has important implications for the sustainable development of the agricultural and natural resource sectors. However, the development of this industry requires significant investment in research and infrastructure as well as policies for efficient and equitable transfer of technologies from the public to the private sector. It is likely that we will observe in the (near) future the emergence of multiple recommendations for policy and institutional designs conducive to the development and deployment of biofuels (in South Korea and elsewhere). We are also likely to observe a demand for tools to assess biofuel policies' economic and environmental impacts-the creation of such tools should be a major priority. To this end, it is important to understand the biofuel industry as a whole and identify potential supply chain structures that could secure the biofuel production levels required to achieve the policy goals set in the political arena.

Finally, much thought needs to be given to the benefits of biofuel production vis-à-vis the benefits of possible alternative uses of the biomass resource. In particular, biomass can be used to produce electricity, and the technologies therein can become carbon-negative (i.e., bioenergy with carbon capture and storage). Biomass-based electricity can then be utilized as a transportation fuel, especially in areas where the driving distances are not long. Biomass can also be used to produce hydrogen and/or ammonia, and even though the relevant technologies are very far from commercialization, their long-run potential is enormous.

\section{Concluding Remarks}

The introduction of biofuels into South Korea's transportation sector can be highly beneficial, mitigating the sector's contribution to GHG emissions as well as creating economic value and improving South Korea's balance of trade. Before showing the benefits to the Korean economy from the introduction of biofuels, we approximated the theoretical (i.e., upper-bound) biomass potential from forestry residues, livestock manure, and staple crops and used the existing literature to calculate the theoretical amount of fuel that could be generated using these different biomass feedstocks. This preliminary analysis suggests that the biofuel potential of South Korea is very substantial, with the 
most promising feedstock being forestry residues. Out of all the technologies considered, the production of cellulosic ethanol from forestry residues could potentially impact the fuel market the most.

We subsequently used a linear demand and supply system for the fuel market and calibrated it taking the own-price demand and supply elasticities from the literature. To address any uncertainty in relation to our model's parameters, we performed Monte Carlo simulations. More specifically, we simulated different biofuel supply-shock scenarios while randomly perturbing the demand and supply elasticities (separately). Our analysis illustrates that the introduction of biofuels leads to an increase in the total amount of fuel consumed and a decrease in the market price of fuel. As a result, an environmentally detrimental rebound effect arises whereby gasoline consumption declines by less than the amount of the biofuels introduced. For example, when perturbing the demand elasticity and under an ambitious scenario of a $25 \%$ biofuel supply shock, the total quantity of gasoline consumed decreases (on average) by only $8.7 \%$, implying a $65.2 \%$ rebound effect. However, $\mathrm{CO}_{2}$ emissions are still mitigated by 0.27 million tonnes, and aggregate welfare in the economy does rise.

Author Contributions: G.H.: Conceptualization, $60 \%$; methodology, $60 \%$; software, $60 \%$; validation, $50 \%$; formal analysis, $65 \%$; investigation, $50 \%$; resources, 50\%; data curation, 50\%; writing-original draft preparation, $40 \%$; writing-review and editing, $40 \%$; visualization, $50 \%$; supervision, $50 \%$; project administration, $50 \%$; funding acquisition, 30\%. C.T.: Conceptualization, $40 \%$; methodology, $40 \%$; software, $40 \%$; validation, $50 \%$; formal analysis, 35\%; investigation, 50\%; resources, 50\%; data curation, 50\%; writing-original draft preparation, $60 \%$; writing-review and editing, $60 \%$; visualization, $50 \%$; supervision, $50 \%$; project administration, $50 \%$; funding acquisition, $70 \%$. All authors have read and agreed to the published version of the manuscript.

Funding: This research was funded by the Korea Development Institute under an Adjunct Fellow appointment of Chrysostomos Tabakis during 09/15/2016—09/14/2017.

Acknowledgments: This paper is written based on Hochman, Gal, and Tabakis, Chrysostomos, "Biomass to Fuel: The Case of South Korea," Korea Development Institute Working Paper 2017-01, 2017. The authors thank the editor and three anonymous referees for constructive and insightful comments that significantly improved the paper. The authors infinitely thank Saketh Aleti, DongWhoi Moon, and Heejung Yun for excellent research assistantship. Any remaining errors are the authors' doing.

Conflicts of Interest: The authors declare no conflict of interest.

\section{References}

1. BP. BP Statistical Review of World Energy; BP: London, UK, 2020.

2. U.S. Energy Information Administration. Country Analysis Brief: South Korea; U.S. Energy Information Administration: Washington, DC, USA; U.S. Department of Energy: Washington, DC, USA, 2018.

3. Kafle, S.; Parajuli, R.; Bhattarai, S.; Euh, S.H.; Kim, D.H. A review on energy systems and GHG emissions reduction plan and policy of the Republic of Korea: Past, present, and future. Renew. Sustain. Energy Rev. 2017, 73, 1123-1130. [CrossRef]

4. Nam, W.-H.; Baigorria, G.A.; Hong, E.-M.; Kim, T.; Choi, Y.-S.; Feng, S. The fingerprint of climate change and urbanization in South Korea. Atmosphere 2018, 9, 273. [CrossRef]

5. International Energy Agency. Transport, Energy and $\mathrm{CO}_{2}$ : Moving toward Sustainability; International Energy Agency: Paris, France; OECD: Paris, France, 2009.

6. U.S. Energy Information Administration. International Energy Outlook 2016; U.S. Energy Information Administration: Washington, DC, USA; U.S. Department of Energy: Washington, DC, USA, 2016.

7. Chakravorty, U.; Hubert, M.-H.; Nøstbakken, L. Fuel versus food. Ann. Rev. Resour. Econ. 2009, 1, 645-663. [CrossRef]

8. Hochman, G.; Rajagopal, D.; Timilsina, G.; Zilberman, D. Quantifying the causes of the global food commodity price crisis. Biomass Bioenergy 2014, 68, 106-114. [CrossRef]

9. Hochman, G.; Zilberman, D. Corn ethanol and U.S. biofuel policy 10 years later: A quantitative assessment. Am. J. Agricult. Econ. 2018, 100, 570-584. [CrossRef]

10. Searchinger, T.; Heimlich, R.; Houghton, R.A.; Dong, F.; Elobeid, A.; Fabiosa, J.; Tokgoz, S.; Hayes, D.; $\mathrm{Yu}, \mathrm{T}$.-H. Use of U.S. croplands for biofuels increases greenhouse gases through emissions from land-use change. Science 2008, 319, 1238-1240. [CrossRef] 
11. Hertel, T.W.; Golub, A.A.; Jones, A.D.; O’Hare, M.; Plevin, R.J.; Kammen, D.M. Effects of US maize ethanol on global land use and greenhouse gas emissions: Estimating market-mediated responses. BioScience 2010, 60, 223-231. [CrossRef]

12. Carriquiry, M.; Elobeid, A.; Dumortier, J.; Goodrich, R. Incorporating sub-national Brazilian agricultural production and land-use into U.S. biofuel policy evaluation. Appl. Econ. Perspect. Policy 2020, 42, 497-523. [CrossRef]

13. Taheripour, F.; Tyner, W.E. US biofuel production and policy: Implications for land use changes in Malaysia and Indonesia. Biotechnol. Biofuels 2020, 13, 11. [CrossRef]

14. International Energy Agency. From 1st- to 2nd-Generation Biofuel Technologies: An Overview of Current Industry and RDED Activities; International Energy Agency: Paris, France; OECD: Paris, France, 2008.

15. International Renewable Energy Agency. Advanced Biofuels. What Holds Them Back? International Renewable Energy Agency: Abu Dhabi, UAE, 2019.

16. Kang, S.; Selosse, S.; Maïzi, N. Strategy of bioenergy development in the largest energy consumers of Asia (China, India, Japan and South Korea). Energy Strategy Rev. 2015, 8, 56-65. [CrossRef]

17. Lim, S.-Y.; Kim, H.-J.; Yoo, S.-H. Public's willingness to pay a premium for bioethanol in Korea: A contingent valuation study. Energy Policy 2017, 101, 20-27. [CrossRef]

18. Lee, J.-S.; Lee, J.-P.; Park, J.-Y.; Lee, J.-H.; Park, S.-C. Status and perspectives on bioenergy in Korea. Renew. Sustain. Energy Rev. 2011, 15, 4884-4890. [CrossRef]

19. Goldemberg, J.; Teixeira Coelho, S.; Nastari, P.M.; Lucon, O. Ethanol learning curve-The Brazilian experience. Biomass Bioenergy 2004, 26, 301-304. [CrossRef]

20. Chen, X.; Khanna, M. Explaining the reductions in US corn ethanol processing costs: Testing competing hypotheses. Energy Policy 2012, 44, 153-159. [CrossRef]

21. Lee, C.-Y.; Huh, S.-Y. Forecasting new and renewable energy supply through a bottom-up approach: The case of South Korea. Renew. Sustain. Energy Rev. 2017, 69, 207-217. [CrossRef]

22. Binod, P.; Sindhu, R.; Singhania, R.R.; Vikram, S.; Devi, L.; Nagalakshmi, S.; Kurien, N.; Sukumaran, R.K.; Pandey, A. Bioethanol production from rice straw: An overview. Bioresour. Technol. 2010, 101, 4767-4774. [CrossRef]

23. Lee, O.K.; Seong, D.H.; Lee, C.G.; Lee, E.Y. Sustainable production of liquid biofuels from renewable microalgae biomass. J. Ind. Eng. Chem. 2015, 29, 24-31. [CrossRef]

24. Hong, J.W.; Jo, S.-W.; Yoon, H.-S. Research and development for algae-based technologies in Korea: A review of algae biofuel production. Photosynth. Res. 2015, 123, 297-303. [CrossRef]

25. Kim, S.J.; Kim, M.Y.; Jeong, S.J.; Jang, M.S.; Chung, I.M. Analysis of the biomass content of various Miscanthus genotypes for biofuel production in Korea. Ind. Crops Prod. 2012, 38, 46-49. [CrossRef]

26. Searle, S.Y.; Malins, C.J. Waste and residue availability for advanced biofuel production in EU Member States. Biomass Bioenergy 2016, 89, 2-10. [CrossRef]

27. Börjesson Hagberg, M.; Pettersson, K.; Ahlgren, E.O. Bioenergy futures in Sweden-Modeling integration scenarios for biofuel production. Energy 2016, 109, 1026-1039. [CrossRef]

28. Rajagopal, D.; Plevin, R.; Hochman, G.; Zilberman, D. Multi-objective regulations on transportation fuels: Comparing renewable fuel mandates and emission standards. Energy Econ. 2015, 49, 359-369. [CrossRef]

29. Korean Statistical Information Service (KOSIS). Available online: http://kosis.kr/statisticsList/statisticsList_ 01List.jsp? vwcd=MT_ZTITLE\&parentId=F (accessed on 27 April 2017).

30. Food and Agriculture Organization of the United Nations (FAO). Available online: http://www.fao.org/ faostat/en/\#data/QC (accessed on 1 April 2017).

31. Stoft, S. Renewable Fuel and the Global Rebound Effect; Global Energy Policy Center Research Paper \#10-06; Global Energy Policy Center: Berkeley, CA, USA, 2010.

32. Hochman, G.; Rajagopal, D.; Zilberman, D. The effect of biofuels on the international oil market. Appl. Econ. Perspect. Policy 2011, 33, 402-427. [CrossRef]

33. Tyner, W.E.; Taheripour, F.; Zhuang, Q.; Birur, D.; Baldos, U. Land Use Changes and Consequent $\mathrm{CO}_{2}$ Emissions due to US Corn Ethanol Production: A Comprehensive Analysis; Mimeo; Purdue University: West Lafayette, IN, USA, 2010.

34. De Gorter, H.; Just, D.R. The economics of a blend mandate for biofuels. Am. J. Agric. Econ. 2009, 91, 738-750. [CrossRef] 
35. Kofman, P.D. Units, Conversion Factors and Formulae for Wood for Energy; (Harvesting/Transportation) COFORD: Dublin, Ireland, 2010; Volume 21.

36. NJ. 2011 New Jersey Energy Master Plan. State of New Jersey. 2011. Available online: http://nj.gov/emp/ docs/pdf/2011_Final_Energy_Master_Plan.pdf (accessed on 27 April 2017).

37. Hochman, G.; Timilsina, G.R. Fuel Efficiency versus Fuel Substitution in the Transport Sector: An Econometric Analysis; World Bank Policy Research Working Paper \#8070; World Bank Group: Washington, DC, USA, 2017.

38. Rajagopal, D.; Sexton, S.E.; Roland-Holst, D.; Zilberman, D. Challenge of biofuels: Filling the tank without emptying the stomach? Environ. Res. Lett. 2007, 2, 1-9. [CrossRef]

39. Hochman, G.; Sexton, S.E.; Zilberman, D.D. The economics of biofuel policy and biotechnology. J. Agric. Food Ind. Organ. 2008, 6. [CrossRef]

40. Brennan-Tonetta, M.; Hochman, G.; Schilling, B. Impact of political economy and logistical constraints on assessments of biomass energy potential: New Jersey as a case study. In Modeling, Dynamics, Optimization and Bioeconomics, I; Pinto, A.A., Zilberman, D., Eds.; Springer Proceedings in Mathematics \& Statistics 73; Springer: Berlin, Germany, 2014.

41. National Renewable Energy Laboratory. NREL Proves Cellulosic Ethanol Can Be Cost Competitive; Innovation Impact: Bioenergy; National Renewable Energy Laboratory: Golden, CO, USA, 2013.

42. Moriarty, K.; Milbrandt, A.; Lewis, J.; Schwab, A. 2017 Bioenergy Industry Status Report; National Renewable Energy Laboratory: Golden, CO, USA, 2020.

43. Khana, M.; Zilberman, D. Handbook of Bioenergy Economics and Policy: Volume II; Khanna, M., Zilberman, D., Eds.; Natural Resource Management and Policy; Springer: Berlin, Germany, 2017; Volume 40.

44. Korea Energy Agency (KEA). Available online: https://www.energy.or.kr/renew_eng/new/rfs.aspx (accessed on 14 May 2017).

45. Shin, J.-Y.; Kim, G.-W.; Zepernick, J.S.; Kang, K.-Y. A comparative study on the RFS program of Korea with the US and UK. Sustainability 2018, 10, 4618. [CrossRef]

46. International Energy Agency-Advanced Motor Fuels (IEA-AMF). Available online: https://iea-amf.org/ content/publications/country_reports/korea (accessed on 14 May 2017).

(C) 2020 by the authors. Licensee MDPI, Basel, Switzerland. This article is an open access article distributed under the terms and conditions of the Creative Commons Attribution (CC BY) license (http://creativecommons.org/licenses/by/4.0/). 